\title{
En recuerdo de Leonardo Polo
}

\author{
José Ignacio Murillo \\ Universidad de Navarra
}

Leonardo Polo nació en Madrid en 1926. Su padre, abogado de profesión, que había sido teniente de alcalde en esa ciudad y desempeñó el puesto de fiscal jefe durante la guerra civil, hubo de salir del país al final de la contienda y murió en Chile unos años después, sin poder reunirse de nuevo con su familia en 1948. Pocos años después de este drama familiar, conoció a San Josemaría Escrivá de Balaguer, cuya paternidad espiritual supuso una inspiración en su vida personal, también en su vocación intelectual. Entre otras cosas, contribuyó a situar en el centro de su tarea intelectual la libertad, que no fue para él solo un tema de estudio, sobre el que reflexionó infatigablemente, sino una característica central del modo en que concebía el ejercicio del pensar. Al escucharle se palpaba que no concebía la fe cristiana como un límite, sino como una liberación de la inteligencia y un acicate para no conformarse.

Estudió Derecho, siguiendo la tradición familiar, aunque pronto descubrió que su vocación no era la práctica jurídica, sino la teoría, y comenzó Filosofía y Letras y los estudios de doctorado. Tras una estancia de investigación en Italia, volvió a España en 1954 para impartir clases en la Universidad de Navarra, y, al crearse la Facultad de Filosofía y Letras, se convirtió en uno de sus primeros profesores. Salvo los dos años que permaneció en Granada, en cuya Universidad obtuvo la cátedra en 1966, su vida y su labor académica discurrieron en esa universidad, donde, de un modo discreto, se entregó a la realización de un ambicioso proyecto intelectual, ya entrevisto en sus años de juventud, que fue desarrollando con esfuerzo, rigor y tenacidad a lo largo de toda su vida académica.

Aunque su filosofía se resiste a ser clasificada, su labor se puede inscribir en el empeño de muchos de sus contemporáneos por revisar y encauzar el proyecto intelectual de la modernidad. Pero, a diferencia de buena parte de ellos, en quienes tanto el balance como la propuesta adquieren tintes pesimistas o desesperanzados, su propuesta es optimista y, sin abandonar la confianza en la capacidad humana de conocer, se propone rectificar e integrar todas las aportaciones valiosas, arrojando más luz sobre los temas.

A lo largo de su tarea docente ha contribuido a la formación de numerosas personas, no solo en España, sino también en otras universidades del mundo,

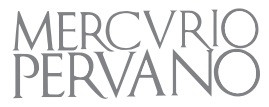


especialmente de Hispanoamérica, con un magisterio desinteresado, ajeno a los personalismos. No era amigo de las escuelas. Prefería entender la filosofía como la tarea de incorporarse al diálogo con todos aquellos que, a lo largo de la historia, se han empeñado seriamente en la búsqueda de la verdad; $y$, aunque sostenía que la originalidad no es un valor en filosofía, impulsaba siempre a todos a no conformarse con lo ya sabido y a enriquecerlo con la propia investigación.

Esto no ha impedido que muchas personas se consideren sus discípulos y hayan intentado desarrollar lo que de él han aprendido. Numerosas tesis doctorales, no pocos libros y dos revistas académicas dedicadas a su pensamiento dan prueba de la fecundidad de sus aportaciones en muchas áreas de la filosofía y del conocimiento en general, expuestas en numerosos libros, que han ido viendo la luz sobre todo en los últimos tres decenios. Son muchas las personas que han aprendido a pensar escuchándolo en sus clases o en conversaciones informales. En ellas, al margen de adornos o de efusiones sentimentales, la filosofía se manifestaba como un ejercicio apasionante, que despertaba las fibras más hondas de la existencia. Quienes hemos tenido la fortuna de conocer el pensamiento de Leonardo Polo y estudiarlo con detenimiento estamos convencidos de que es una de las mentes más lúcidas y vigorosas de nuestro tiempo. 